\title{
DOT1L regulates dystrophin expression and is critical for cardiac function
}

\author{
Anh T. Nguyen, ${ }^{1,2}$ Bin Xiao, ${ }^{3}$ Ronald L. Neppl, ${ }^{4}$ Eric M. Kallin, ${ }^{1,2,6}$ Juan Li, $^{3}$ Taiping Chen, ${ }^{5}$ \\ Da-Zhi Wang, ${ }^{4}$ Xiao Xiao, ${ }^{3}$ and Yi Zhang ${ }^{1,2,7}$ \\ ${ }^{1}$ Howard Hughes Medical Institute, University of North Carolina at Chapel Hill, North Carolina 27599 , USA; ${ }^{2}$ Department \\ of Biochemistry and Biophysics, Lineberger Comprehensive Cancer Center, University of North Carolina at Chapel Hill, North \\ Carolina 27599, USA; ${ }^{3}$ Division of Molecular Pharmaceutics, University of North Carolina at Chapel Hill, North Carolina \\ 27599, USA; ${ }^{4}$ Department of Cardiology, Children's Hospital Boston, Harvard Medical School, Boston, Massachusetts 02115, \\ USA; ${ }^{5}$ Novartis Institutes for Biomedical Research, Cambridge, Massachusetts 02139, USA
}

Histone methylation plays an important role in regulating gene expression. One such methylation occurs at Lys 79 of histone $\mathrm{H} 3(\mathrm{H} 3 \mathrm{~K} 79)$ and is catalyzed by the yeast DOT1 (disruptor of telomeric silencing) and its mammalian homolog, DOT1L. Previous studies have demonstrated that germline disruption of Dot1L in mice resulted in embryonic lethality. Here we report that cardiac-specific knockout of Dot1L results in increased mortality rate with chamber dilation, increased cardiomyocyte cell death, systolic dysfunction, and conduction abnormalities. These phenotypes mimic those exhibited in patients with dilated cardiomyopathy (DCM). Mechanistic studies reveal that DOT1L performs its function in cardiomyocytes through regulating Dystrophin (Dmd) transcription and, consequently, stability of the Dystrophin-glycoprotein complex important for cardiomyocyte viability. Importantly, expression of a miniDmd can largely rescue the DCM phenotypes, indicating that Dmd is a major target mediating DOT1L function in cardiomyocytes. Interestingly, analysis of available gene expression data sets indicates that DOT1L is down-regulated in idiopathic DCM patient samples compared with normal controls. Therefore, our study not only establishes a critical role for DOT1L-mediated H3K79 methylation in cardiomyocyte function, but also reveals the mechanism underlying the role of DOT1L in DCM. In addition, our study may open new avenues for the diagnosis and treatment of human heart disease.

[Keywords: DOT1L; H3K79 methylation; cardiomyopathy; dystrophin]

Supplemental material is available for this article.

Received April 19, 2010; revised version accepted December 23, 2010.

Chromatin is subject to reversible post-translational modifications that may alter chromatin structure and function directly, or indirectly through the recruitment of effector proteins at heterochromatic (silenced) and euchromatic (active) DNA. Histone methylation plays an important role in regulating transcription at target loci and is important for $\mathrm{X}$ inactivation, cell fate maintenance, and terminal differentiation (Peterson and Laniel 2004; Martin and Zhang 2005; Kouzarides 2007). One particular histone methylation event occurs at Lys 79 within the globular domain of histone $\mathrm{H} 3(\mathrm{H} 3 \mathrm{~K} 79)$ and is catalyzed by yeast DOT1 (disruptor of telomeric silencing) and its mammalian homolog, DOT1L (Feng et al. 2002; Lacoste et al. 2002; Ng et al. 2002a; van Leeuwen et al. 2002). Although DOT1 was originally identified as a regulator of telomeric silencing (Singer et al. 1998),

${ }^{6}$ Present address: Department of Differentiation and Cancer, Centre de Regulacio Genomica, Barcelona 08003, Spain.

${ }^{7}$ Corresponding author.

E-MAIL yi_zhang@med.unc.edu; FAX (919) 966-4330.

Article is online at http://www.genesdev.org/cgi/doi/10.1101/gad.2018511. more recent studies suggest that DOT1-mediated H3K79 methylation is linked to euchromatic gene transcription (Schubeler et al. 2004; Barski et al. 2007; Steger et al. 2008).

In yeast, DOT1 activity is positively regulated during transcription elongation through Rad6-Bre1 monoubiquitination of $\mathrm{H} 2 \mathrm{~B}$ (Ng et al. 2002b; Krogan et al. 2003; Wood et al. 2003). Additionally, DOT1 has been linked to the meiotic pachytene checkpoint control (San-Segundo and Roeder 2000) and DNA damage repair (Giannattasio et al. 2005; Wysocki et al. 2005; Conde et al. 2009). However, the biological function of mammalian DOT1L, particularly in the context of the animal, is less characterized. A recent study indicates that DOT1L exists in a large protein complex and regulates the expression of Wingless target genes (Mohan et al. 2010). We and others demonstrated previously that mistargeting of DOT1L and subsequent H3K79 hypermethylation play an important role in leukemic transformation (Okada et al. 2005, 2006; Mueller et al. 2007; Krivtsov et al. 2008). Most recently, DOT1L has been shown to regulate the erythroid and 
myeloid lineage switch during differentiation (Feng et al. 2010). In addition, loss-of-function studies revealed a critical role of DOT1L during mouse embryogenesis, as germline Dot11 knockout (KO) causes lethality at embryonic day 10.5 (E10.5) with growth impairment, yolk sac angiogenesis defects, and cardiac dilation (Jones et al. 2008).

Congestive heart failure (CHF) is a common manifestation of cardiomyopathy, a disease caused by malfunction of the heart muscle (Seidman and Seidman 2001; Liew and Dzau 2004). Dilated cardiomyopathy (DCM) is characterized by dilation of the left or both ventricles and reduced contractile function (systolic dysfunction), and is the most prevalent form of cardiomyopathy (Seidman and Seidman 2001; Liew and Dzau 2004). Recent studies suggest that, in addition to genetic alterations, epigenetic factors also contribute to DCM. For example, several studies have linked histone acetylation to cardiac hypertrophy and DCM (Zhang et al. 2002; Kook et al. 2003; Montgomery et al. 2007; Ha et al. 2010; Hang et al. 2010). However, whether histone methylation contributes to DCM is not clear, although dysregulation of histone methylation has been linked to a number of human diseases (Feinberg et al. 2002; Handel et al. 2009).

To further characterize the function of DOT1L in the mouse heart, we generated a cardiomyocyte-specific KO mouse model using the $\alpha$-MHC ( $\alpha$-myosin heavy chain)Cre line and demonstrate that DOT1L plays an important role in heart function. We provide evidence suggesting that dysregulation of Dystrophin in cardiomyocytes is largely responsible for the phenotypes exhibited in the Dot1L cardiac conditional KO mice.

\section{Results}

Dot1L deficiency in cardiomyocytes does not cause embryonic lethality

Previous studies demonstrate that germline Dot11 KO causes lethality at E10.5 with diverse impairments that include growth retardation, yolk sac angiogenesis defects, and cardiac dilation (Jones et al. 2008). To understand the molecular mechanism underlying the embryonic phenotypes, we took advantage of the fact that the Dot $1 \mathrm{~L}$ conditional allele contains a promoterless $\beta$-geo cassette (Jones et al. 2008), and analyzed Dot1L expression by $\mathrm{X}$-gal staining. This study revealed that the heart is one of the highest Dot $1 L$-expressing organs (Supplemental Fig. 1A). RT-qPCR analysis also indicates that cardiac expression of Dot1L peaks after birth (Supplemental Fig. 1B). This Dot $1 L$ expression pattern in combination with the timing of lethality suggests that heart defects might contribute to the embryonic lethality phenotype.

To explore a role for DOT1L in the heart, we generated a cardiac-specific conditional KO mouse model by first crossing DOT1L $L^{210 x /+}$ and $D O T 1 L^{110 x /+}$ with the $\alpha-M H C$-Cre line (Supplemental Fig. 2A; Abel et al. 1999). Cardiac conditional KO (referred to as CKO hereafter), DOT1L ${ }^{210 x / 110 x} ; \alpha$-MHC-Cre, mice were then obtained by crossing $D O T 1 L^{2 l o x /+} ; \alpha$-MHC-Cre mice with
${ }_{\text {DOT } 1 L^{1 l o x /+}} ; \alpha$-MHC-Cre mice. Cre-mediated deletion results in removal of 108 amino acids in the catalytic domain of DOT1L, rendering an enzymatically inactive DOT1L (Supplemental Fig. 2B). CKO mice were born at Mendelian ratio (Supplemental Fig. 2C), and recombination efficiency was verified by RT-qPCR using hearts derived from newborn, postnatal day 1 (P1) mice (Supplemental Fig. 2D). Consistent with loss-of-function of DOT1L in the CKO hearts, Western blot analysis and immunostaining using an antibody that recognizes both di- and trimethylation of H3K79 (H3K79me2/3) demonstrate loss of H3K79me2/3 in the CKO hearts (Supplemental Fig. 2E,F). These results suggest that loss-of-function of DOT1L in cardiomyocytes alone is not sufficient to cause embryonic lethality.

\section{Dot1L deficiency in cardiomyocytes causes heart dilation and postnatal lethality}

Although CKO mice are born at Mendelian ratio, sudden death was observed in $50 \%$ of the CKO mice within 2 wk after birth, and the remaining $50 \%$ of the CKO mice died by $6 \mathrm{mo}$ of age (Fig. 1A), indicating that DOT1L has an important function in postnatal and adult cardiomyocytes. Analysis of the CKO mice revealed severely enlarged hearts (Fig. 1B) and dilation of both chambers (Fig. 1C). Consistently, heart to body weight ratios were also increased in CKO mice compared with that of their littermate controls (Fig. 1D). The increased heart to body weight ratio is caused mainly by increased heart weight (Fig. 1E), as the body weight is not significantly altered between wild-type and CKO mice (Supplemental Fig. 3A).

To determine whether concentric hypertrophy contributes to the increase in CKO heart mass, tissue sections were stained with Laminin antibody followed by measuring cardiomyocyte circumference. Quantification using ImageJ software indicates that the average cell circumference is not altered in CKO mice (Supplemental Fig. $3 \mathrm{~B}, \mathrm{C})$, suggesting that the increase in CKO heart mass is due in part to eccentric hypertrophy. These data collectively indicate that loss of DOT1L function-particularly its H3K79 methyltransferase activity-in cardiomyocytes results in CHF that is likely due to DCM.

\section{CKO hearts exhibit similar cardiac remodeling observed in DCM patients}

In addition to chamber dilation, gross changes in heart morphology (such as deviation from an elliptical shape to a more spherical one and increased heart mass) were also observed (Fig. 1C,E), indicating that loss-of-function of DOT1L in cardiomyocytes caused cardiac remodeling. Since DCM is often accompanied by pathologic remodeling (Cohn et al. 2000), we analyzed the histopathology of CKO hearts at P10. TUNEL staining revealed a dramatic increase in apoptotic cell death in CKO hearts compared with the wild-type control (Fig. 2A). In addition, transmission electron microscopic (TEM) analysis revealed a significant increase of vacuoles in CKO myocytes (Fig. $2 \mathrm{~B}$, panel ii, arrows), suggesting an increase in autophagic 

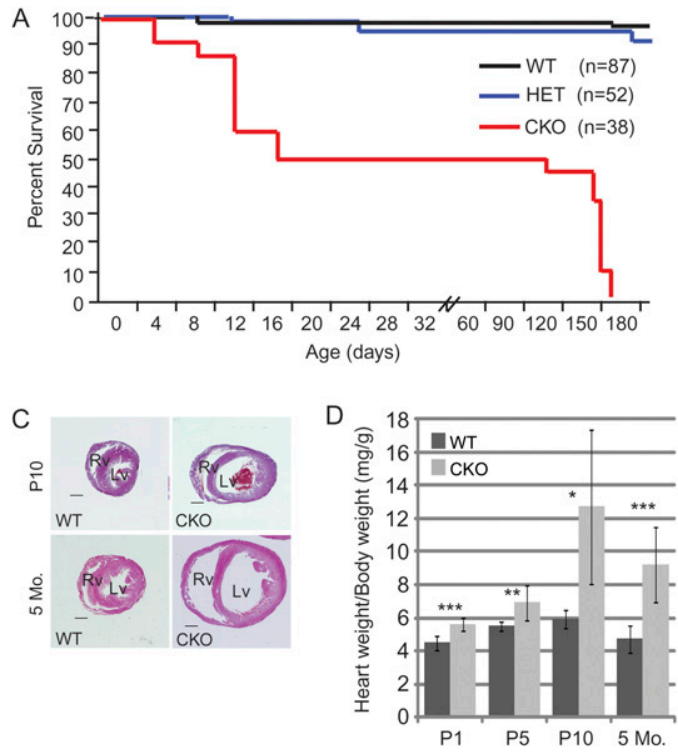

B
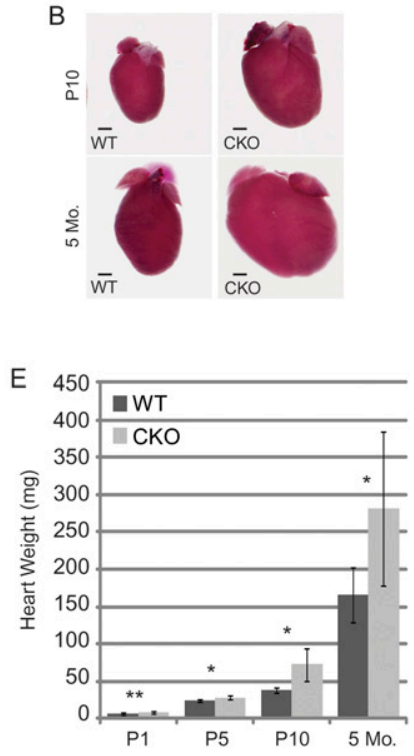

Figure 1. Disruption of DOT1L function in mouse cardiomyocytes results in heart dilation and lethality. (A) Dot1L CKO in mouse heart causes postnatal and adult lethality. Survival curves of wild-type (WT), HET, and CKO mice. Fifty percent of CKO mice die within the first $2 \mathrm{wk}$ after birth and the remaining $50 \%$ die by $6 \mathrm{mo}$ of age. (B) CKO hearts are severely enlarged compared with wild type (WT). Shown are wildtype and CKO hearts harvested from P10 and 5 -mo-old adult mice, respectively. Bar, $1 \mathrm{~mm} .(C)$ H\&E staining of paraffin tissue sections indicated that $\mathrm{CKO}$ hearts are enlarged due to ventricular chamber dilation. Bar, $1 \mathrm{~mm}$. $(D)$ CKO mice have increased heart to body weight ratios. Heart weight (milligrams) to body weight (grams) ratios were calculated using an analytical balance. CKO mice have increased ratios compared with wild-type littermates. $\left(^{\star}\right) P<$ 0.06; $\left.{ }^{\star \star \star}\right) P<0.006 ;\left(^{\star \star \star}\right) P<0.0006 .(E)$ CKO mice have increased heart weight. Heart weight (milligrams) was measured using an analytical balance. $\left(^{\star}\right) P<0.06$. cell death, consistent with previous studies linking autophagy to DCM (Knaapen et al. 2001). In addition, TEM also revealed interstitial fibroblast cells in CKO heart tissue (Fig. 2B, cf. panels $i$ and iii), indicating that reactive fibrosis, a common feature of cardiac remodeling found in DCM (de Leeuw et al. 2001; Luk et al. 2009), took place in CKO hearts. Additionally, immunostaining with anti-HSPG2 (also known as Perlecan) shows increased interstitial HSPG2 staining (Fig. 2C, arrowheads) as well as increased HSPG 2 and myofibroblasts lining the inner left ventricular chamber (Fig. 2C, yellow outlined) in CKO hearts, supporting the presence of reactive fibrosis, which is further confirmed by Masson's trichrome staining (Fig. 2D, blue staining).

Previous studies have established that reactivation of a fetal gene expression program and increase in cellular proliferation is concomitant with the degeneration of cardiomyocytes in DCM (Kajstura et al. 1998; Cohn et al. 2000; Houweling et al. 2005). Consistent with the notion that DOT1L deficiency resulted in DCM,
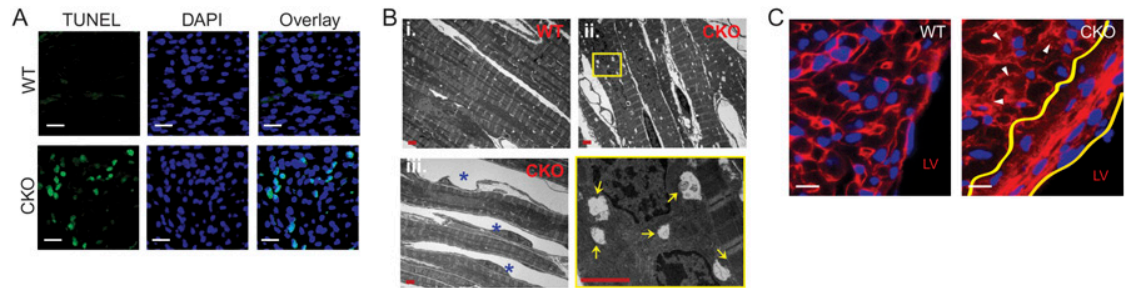

D

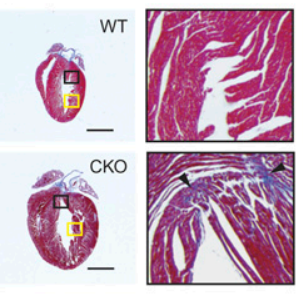

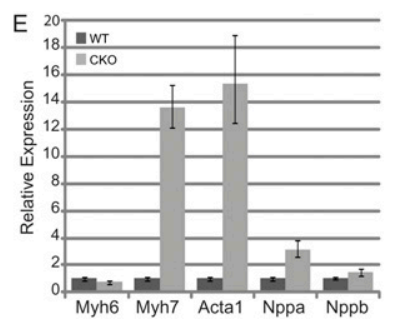

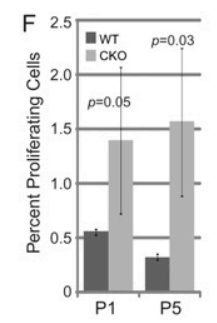

Figure 2. Disruption of DOT1L function in mouse cardiomyocytes results in pathologic cardiac remodeling. (A) Positive TUNEL staining (green) merged with DAPI (blue) demonstrates increased cell death in CKO hearts (P10; bar, $5 \mu \mathrm{m})$. (B) TEM analysis of P10 hearts demonstrates increased autophagic cell death (cf. panels

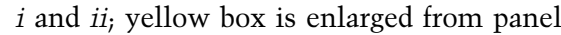
$i i$; vacuoles are indicated by yellow arrows; bar, $2 \mu \mathrm{m}$ ) and myofibroblast infiltration (indicated by asterisk [*] in panel iii) in CKO hearts. Note that myocytes in wildtype (WT) hearts show tight lateral association, whereas myocytes in CKO hearts have large gaps due to myofibroblast infiltration. (C) Increased interstitial ECM, indicated by staining of the ECM component HSPG2 (red), is observed in the CKO hearts (arrowheads). Increased ECM and myofibroblasts lining the inner left ventricular chamber wall (between the two yellow lines) is also observed in CKO hearts. Bar, $10 \mu \mathrm{m}$. (D) Masson's trichrome staining of paraffin tissue sections of mouse hearts (5 mo old). Two enlarged regions are shown (black and yellow boxes). Interstitial fibrosis is seen in CKO hearts, but not in wild-type (WT) counterparts. Bar, $5 \mathrm{~mm}$. (E) RT-qPCR analysis demonstrates activation of fetal-specific genes (Myh7, Acta1, Nppa, and Nppb) in the CKO hearts. In contrast, down-regulation of adult Myh6 is also observed. $(F)$ Increased cell proliferation in CKO hearts (P1 and P5). Frozen tissue sections were stained with anti-Ki-67, a marker of cell proliferation, and counterstained with DAPI. The percentage of proliferating cells was calculated by dividing the number of Ki-67-positive nuclei by total nuclei and multiplying by 100. 
RT-qPCR demonstrated that expression of the fetal genes Myh7, Acta1, Nppa, and Nppb is up-regulated in CKO hearts (Fig. 2E). In contrast, adult gene Myh6 is downregulated. Mouse cardiomyocytes retain a small capacity to proliferate after birth (Ahuja et al. 2007; Banerjee et al. 2007). To determine whether DOT1L deficiency results in an increased cell proliferation, as exhibited in DCM, heart tissue sections were immunostained for Ki-67 at P1 and P5. Results shown in Figure 2F demonstrate that the percentage of proliferating cells (ratio of Ki-67-positive nuclei to total nuclei, multiplied by 100) is significantly increased in the CKO hearts compared with the control, which may contribute to the observed increase in the CKO heart mass. We note that this increased cell proliferation in the DOT1L-deficient heart is in contrast to previous studies showing a requirement for DOT1L in embryonic stem cell cycle progression (Jones et al. 2008; Barry et al. 2009), suggesting cell type specificity. Taken together, the above data support the notion that CKO hearts exhibit multiple phenotypes similar to those observed in DCM.

\section{CKO hearts exhibit similar functional defects observed in DCM patients}

To gain further support that DOT1L deficiency in cardiomyocytes results in DCM, we asked whether the morphological changes and cardiac remodeling observed in CKO hearts affect their function. To this end, we performed echocardiography (ECHO) analysis at different mouse age groups. Conscious ECHOs performed on P10 pups during the first stage of lethality ( $n=5$ per genotype) demonstrated that CKO mice have increased left ventricular internal dimensions and volume. Analysis of cardiac output by measuring ejection fraction (EF) and fractional shortening (FS) revealed that both EF and FS is reduced by almost half in CKO mice when compared with those of wild-type mice (Table 1). These results are indicative of left ventricular systolic dysfunction and are consistent with clinical DCM outcome (Karkkainen and Peuhkurinen 2007; Luk et al. 2009). Similar results were obtained at 2 and 5 mo of age (Table 1). Interestingly, the smaller difference between wild-type and CKO mice at 2 mo may reflect a compensation that allowed these mice to bypass the first stage of lethality.

Cardiac conduction abnormalities are frequently observed in DCM heart failure patients with left ventricular systolic dysfunction (Olson 2004). During heart contraction, an electrical impulse transmits from atria (P-wave) to ventricles (QRS-wave) at the atrioventricular node (AVN). The time delay for electrical propagation can be measured directly by electrocardiography (EKG) (Hatcher and Basson 2009). To determine whether the conduction system is perturbed in CKO mice, EKG was performed at 5 mo of age ( $n=8$ per genotype). All CKO mice displayed minimally a first-degree heart block at the AVN, with an $80 \%$ penetration of either nonsustained ventricular tachycardia ( $n=1$ of 8 ) (Fig. $3 \mathrm{~A}, \mathrm{CKOa})$, periodic thirddegree heart block ( $n=3$ of 8 ), or second-degree Type II heart block ( $n=3$ of 8 ) (Fig. 3A, CKOb). Overall, CKO mice have a significant increase in RR interval (Fig. 3B), PR interval (Fig. 3C), P-wave duration (Fig. 3D), and QRS interval (Fig. 3E). These EKG data from CKO mice are consistent with EKG findings in human DCM patients (Seidman and Seidman 2001; Towbin and Bowles 2006; Luk et al. 2009). The physiological studies further support the notion that DOT1L deficiency in cardiomyocytes confers phenotypes similar to those observed in patients with DCM.

\section{Dot1L deficiency in cardiomyocytes down-regulates dystrophin expression}

Having established that DOT1L deficiency in cardiomyocytes causes phenotypes similar to those observed in DCM, we next attempted to understand the molecular mechanism. To date, mutations in $>30$ genes have been linked to human DCM (Supplemental Table 1) (Towbin and Bowles 2006; Karkkainen and Peuhkurinen 2007; Kimura 2008; Luk et al. 2009). Given that DOT1Lmediated H3K79 methylation is associated with actively transcribed genes (Martin and Zhang 2005; Z Wang et al. 2008), we anticipated that one or more of the DCMassociated genes might be down-regulated due to loss of

Table 1. Heart function of wild-type and CKO mice as measured by ECHO

\begin{tabular}{|c|c|c|c|c|c|c|c|c|c|}
\hline & & $\mathrm{EF}$ & FS & $\begin{array}{l}\text { LVID;d } \\
(\mathrm{mm})\end{array}$ & $\begin{array}{l}\text { LVID;s } \\
(\mathrm{mm})\end{array}$ & $\begin{array}{l}\text { LV Vol:d } \\
\quad(\mu \mathrm{L})\end{array}$ & $\begin{array}{l}\text { LV Vol;s } \\
(\mu \mathrm{L})\end{array}$ & LV mass & $n$ \\
\hline \multicolumn{10}{|l|}{ P10 } \\
\hline & Wild type & $89.20 \% \pm 1.86 \%$ & $56.50 \% \pm 2.69 \%$ & $1.59 \pm 0.13$ & $0.70 \pm 0.08$ & $7.23 \pm 1.58$ & $0.79 \pm 0.28$ & $18.70 \pm 3.01$ & 5 \\
\hline & $\mathrm{CKO}$ & $55.80 \% \pm 3.83 \%$ & $27.30 \% \pm 2.15 \%$ & $2.16 \pm 0.25$ & $1.57 \pm 0.23$ & $15.79 \pm 4.82$ & $7.15 \pm 2.87$ & $21.41 \pm 3.47$ & 5 \\
\hline & $P$-value & $\star \star \star \star$ & $\star \star \star$ & * & $\star \star \star$ & * & $\star \star \star$ & $\mathrm{ns}$ & \\
\hline \multicolumn{10}{|c|}{$2 \mathrm{mo}$} \\
\hline & Wild type & $85.15 \% \pm 4.63 \%$ & $53.47 \% \pm 6.03 \%$ & $2.73 \pm 0.19$ & $1.27 \pm 0.18$ & $27.97 \pm 4.66$ & $4.11 \pm 1.46$ & $76.61 \pm 11.88$ & 6 \\
\hline & $\mathrm{CKO}$ & $72.56 \% \pm 5.77 \%$ & $40.81 \% \pm 4.73 \%$ & $3.12 \pm 0.13$ & $1.85 \pm 0.20$ & $38.83 \pm 4.12$ & $10.87 \pm 2.91$ & $98.51 \pm 18.0$ & 4 \\
\hline & $P$-value & * & * & * & $\star \star$ & * & $\star \star \star$ & ns & \\
\hline \multicolumn{10}{|l|}{$5 \mathrm{mo}$} \\
\hline & Wild type & $84.73 \% \pm 3.60 \%$ & $52.74 \% \pm 4$. & $2.98 \pm 0.28$ & $1.41 \pm 0.19$ & $35.01 \pm 7.72$ & $5.36 \pm 1.81$ & $87.16 \pm 13.89$ & 10 \\
\hline & CKO & $47.02 \% \pm 18.48 \%$ & $24.44 \% \pm 10.84 \%$ & $4.91 \pm 1.43$ & $3.85 \pm 1.60$ & $127.58 \pm 83.67$ & $80.83 \pm 70.08$ & $205.86 \pm 101.11$ & 7 \\
\hline & $P$-value & $\star \star \star$ & $\star \star \star$ & $\star \star$ & $\star \star \star$ & $\star \star$ & $\star \star$ & $\star \star$ & \\
\hline
\end{tabular}

(EF) Ejection fraction; (FS) fractional shortening; (LVID) left ventricular internal diameter; (LV Vol) left ventricular volume; (LV mass) left

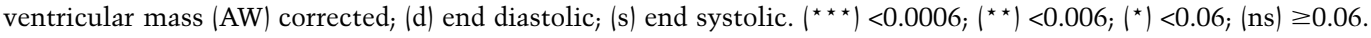




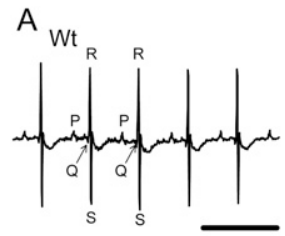

$\mathrm{CKOa}$

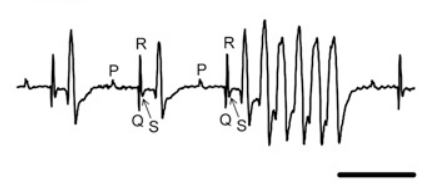

$\mathrm{CKOb}$

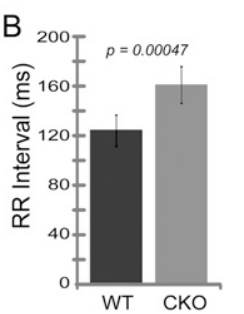

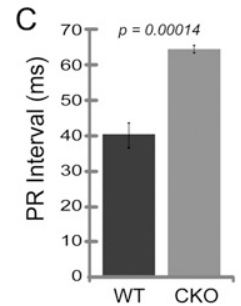
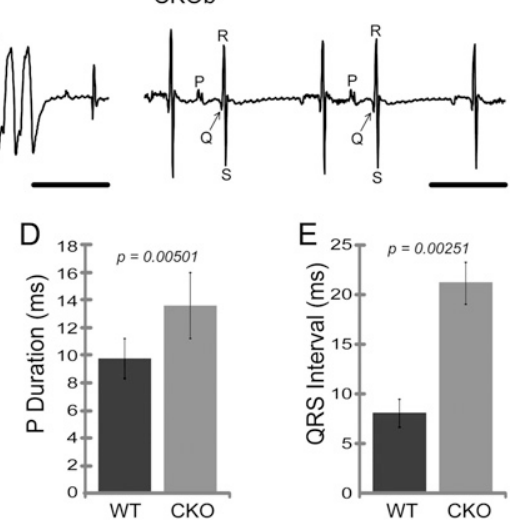

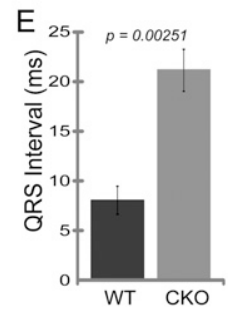

Figure 3. Disruption of DOT1L function in mouse cardiomyocytes results in conduction abnormalities. (A) Representative EKGs for wild-type (Wt) and CKO mice. The analysis was performed using 5-mo-old mice ( $n=8$ per group). CKOa has complete AV dissociation, as evidence by nonsustained ventricular tachycardia, while $\mathrm{CKOb}$ has a Type II second-degree heart block. Bar, $200 \mathrm{msec}$. (B-E) Quantification of EKG data indicated an overall significant increase in $\mathrm{RR}$ interval $(B), \mathrm{PR}$ interval $(C), \mathrm{P}$-wave duration $(D)$, and QRS interval $(E)$. $P$-values were calculated by Student $t$-test.
H3K79 methylation in the CKO heart. To this end, we performed four independent gene expression microarrays using the dual-color Agilent 4X44K Whole Mouse Genome Array system. Data analysis revealed 751 downregulated probes representing 471 genes that are statistically significant, with a false-positive rate of $0.06 \%$ (Supplemental Table 2). Comparison of the microarray data with known DCM-associated genes identified two common genes: Titin (Ttn) and Dystrophin (Dmd).

Ttn is a giant myofilament protein important for maintaining sarcomere structure and elasticity (Kostin et al. 2000). Mutations in Ttn have been reported in autosomal dominant forms of familial DCM /Gerull et al. 2002). Mouse models expressing M-line-deficient Ttn exhibit widened M-lines and gradual disassembly of sarcomeres, which lead to cardiac failure (Gotthardt et al. 2003; Weinert et al. 2006). If Ttn down-regulation is responsible for the DCM in CKO mice, we anticipate an abnormal sarcomere structure in DOT1L CKO hearts. However, TEM analysis revealed that sarcomere integrity is maintained in DOT1L CKO hearts (Supplemental Fig. 4), suggesting that down-regulation of Ttn is not a major contributing factor for the DCM in DOT1L CKO mice.

Dmd was the first discovered DCM-associated gene that can cause both DCM and muscular dystrophy. Dmd is a membrane-associated protein that forms a dystrophin-glycoprotein complex (DGC), which connects contractile sarcomeres to the sarcolemma and extracellular matrix (ECM). This connection is vital for lateral force transduction between cardiomyocytes, as well as for relieving mechanical stress on sarcolemma during contraction (Kostin et al. 2000; Kimura 2008). Since a loss of Dmd expression may be the cause of cell death and cardiac remodeling observed in CKO hearts, we first confirmed the microarray results by RT-qPCR. Data presented in Figure 4A demonstrate that the Dmd mRNA levels are down-regulated to $\sim 25 \%$ of the wild-type level in the CKO hearts. In contrast, expression of other randomly selected DCM-relevant genes (Actn2, Ldb3, Des, and Taz) was not significantly altered by DOT1L deficiency (Fig. 4A). Consistent with a reduction at the RNA level, immunostaining revealed that Dmd protein level is also greatly diminished in CKO hearts (Fig. 4B,C).
Previous studies have demonstrated that mutations affecting expression of Dmd or any sarcoglycan $(S g c)$ gene lead to DGC instability and reduced levels of all complex proteins (Deconinck et al. 1997; Grady et al. 1997). Consistently, immunostaining revealed a great loss of $\beta$-dystroglycan ( $\beta D G$ ) and $\alpha$-sarcoglycan (SGCA) proteins in CKO mice (Fig. 4B,C), although none of the DGC components is altered at the RNA level by DOT1L deficiency (Fig. 4A). These results suggest that loss of Dmd caused degradation of the DGC components, which in turn affects cardiomyocyte viability.

We next sought to determine whether DOT1L directly regulates Dmd expression in the mouse heart by chromatin immunoprecipitation (ChIP). Despite extensive efforts, none of the homemade or commercial DOT1L antibodies (Abgent AP1198a and AP1198b; Cell Signaling D8891 and D8890; and Abcam ab7295) was able to detect endogenous DOT1L protein (data not shown), and thus they are unsuitable for ChIP. Therefore, we performed ChIP assays across the Dmd locus using an antiH3K79me2/3 antibody. Results shown in Figure 4D demonstrate that relatively less $\mathrm{H} 3 \mathrm{~K} 79 \mathrm{me} 2 / 3$ is observed upstream of the Dmd transcription start site (TSS), but it greatly increases downstream, continues to rise at $20 \mathrm{~kb}$ downstream from the TSS, and is still present as far as 59 $\mathrm{kb}$ downstream from the TSS. This H3K79me2/3 distribution pattern is consistent with published ChIP-seq results using various cell lines (Barski et al. 2007; Z Wang et al. 2008). Importantly, the H3K $79 \mathrm{me} 2 / 3$ enrichment on the Dmd gene depends on functional DOT1L, as the enrichment is abolished when samples derived from Dot1L CKO hearts are used. In addition, the detected signals are specific, as enrichment was not observed when IgG was used in a parallel ChIP assay. Previous studies have demonstrated that DOT1L deficiency leads to a complete loss of H3K79 methylation (Jones et al. 2008), indicating that DOT1L is the only H3K79 methyltransferase. The demonstration that H3K 79 methylation of the Dmd gene is dependent on functional DOT1L supports the notion that Dmd is a direct DOT1L target.

It has been reported previously that Dmd expression is positively regulated by the binding of the transcription activator SRF (serum response factor) to a CArG-box 

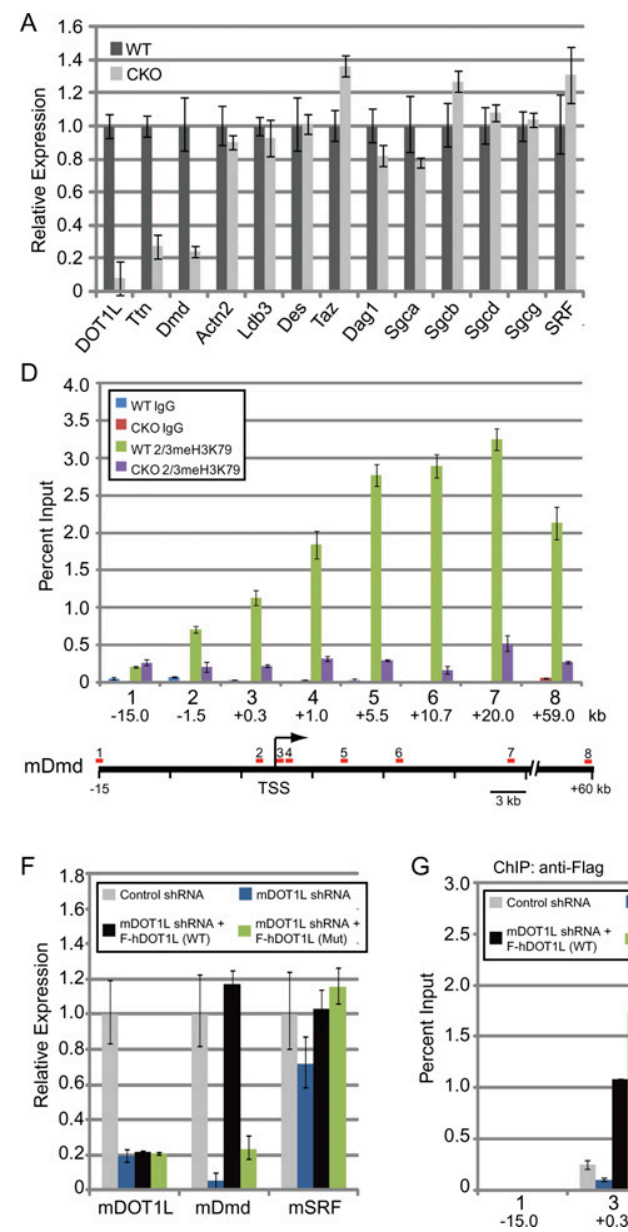
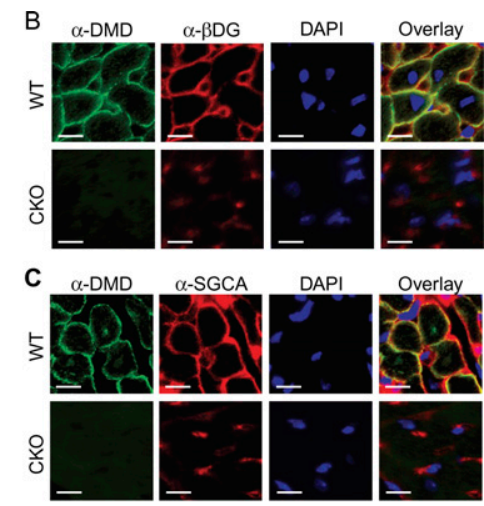

-
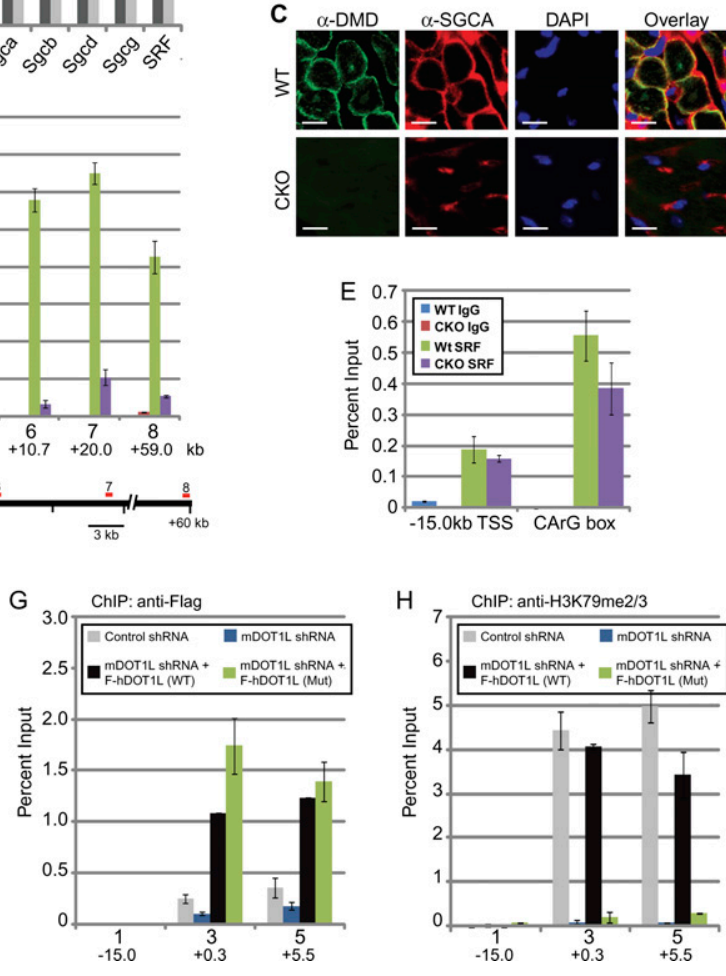

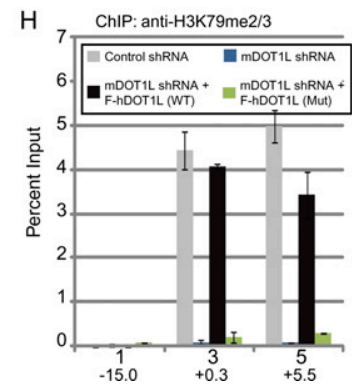

Figure 4. Dystrophin is a direct target of DOT1L. (A) RT-qPCR analysis using RNAs isolated from P10 wild-type (WT) and CKO hearts $(n=12)$. Dmd and Ttn expression is down-regulated in Dot1L CKO hearts. Other members of the DGC (Dag1, Sgca, $S g c b, S g c d$, and $S g c g)$, as well as selected DCM causal genes (Actn2, Ldb3, Des, and $T a z)$, remain unchanged. $(B, C)$ Immunostaining of frozen heart sections demonstrated loss of Dmd protein in CKO hearts (green). Consistent with a Dmd deficiency and complex instability, reduction of $\beta D G$ $(B)$ and SGCA $(C)$ is observed. $(D)$ MicroChIP using heart tissues from P10 pups demonstrates that $\mathrm{H} 3 \mathrm{~K} 79 \mathrm{me} 2 / 3$ is enriched in the gene body of Dmd, and the enrichment is dependent on functional DOT1L. Amplicon \#1 located $\sim 15 \mathrm{~kb}$ upstream of the TSS serves as background for $\mathrm{H} 3 \mathrm{~K} 79 \mathrm{me} 2 / 3$ enrichment. $(E)$ ChIP using an anti-SRF antibody demonstrates that SRF binding to the CArG-box consensus region of the Dmd muscle-specific promoter is not affected in Dot1L CKO hearts. Amplification at the $-15-\mathrm{kb}$ TSS serves as a background for SRF enrichment. ( $F$ ) RT-qPCR analysis demonstrates that Dot $1 L \mathrm{KD}$ in $\mathrm{C} 2 \mathrm{C} 12$ cells results in down-regulation of $\mathrm{Dmd}$. Error bars represent SD of three independent experiments. $(G, H) \mathrm{ChIP}$ analysis demonstrates binding of F-DOT1L to the Dmd locus, and its methylation on $\mathrm{H} 3 \mathrm{~K} 79$ is dependent on DOT1L enzymatic activity. consensus sequence within the muscle-specific Dmd promoter (Galvagni et al. 1997). To examine whether transcription activation by SRF is affected in CKO hearts, we analyzed SRF RNA levels by RT-qPCR. The results shown in Figure 4A demonstrate that SRF expression is not significantly altered in CKO hearts (Fig. 4A). In addition, ChIP analysis using an anti-SRF antibody indicates that SRF binding to the TSS or CArG-box consensus region of Dmd is not affected by Dot1L KO (Fig. 4E). These results support that DOT1L and SRF function independently of each other, and that transcriptional regulation of Dmd by DOT1L-mediated H3K79 methylation functions downstream from SRF.

\section{DOT1L directly regulates dystrophin expression in C2C12 cells}

To further demonstrate that DOT1L directly regulates Dmd expression, we performed lentiviral shRNA knockdown (KD) and retroviral rescue experiments in C2C12 myoblast cells. KD of $m D o t 1 L$ effectively reduced both $m \operatorname{Dot} 1 L$ and Dmd expression compared with control shRNA, whereas Srf is not significantly affected (Fig. 4F). Despite similar expression levels of the wild-type and a catalytic mutant Flag-hDOT1L (Supplemental Fig. 6), Dmd expression is rescued only by wild-type Flag-
hDOT1L, but not the catalytic mutant, indicating that DOT1L-mediated H3K79 methylation is critical for Dmd expression (Fig. 4F). ChIP analysis demonstrates that the effect of DOT1L on Dmd expression is direct, as both wild-type and catalytic mutant Flag-hDOT1L bind to the Dmd locus (Fig. 4G). Consistent with transcriptional regulation of Dmd by DOT1L histone methyltransferase activity, H3K79 methylation is also enriched at the Dmd locus in control shRNA and wild-type Flag-hDOT1L rescued samples, while enrichment is reduced in mDOT1L $\mathrm{KD}$ and catalytic mutant rescued cells (Fig. 4H). Thus, these data establish that H3K79 methylation by DOT1L directly regulates $D m d$ transcription.

\section{Postnatal dystrophin gene delivery and expression in cardiomyocytes rescues cardiac function in CKO mice}

Gene expression and ChIP analyses suggest that DOT1L's role in cardiomyocytes may be mediated through its regulation of Dmd expression. To determine whether Dmd is a key target contributing to the DCM phenotype, we performed in vivo rescue experiments using an adenoassociated virus serotype 9 (AAV9) vector expressing a minidystrophin gene under the control of CMV promoter. AAV-mediated gene therapy with minidystrophin 
has been shown previously to effectively treat dystrophic pathology (Wang et al. 2000). The vector used to rescue Dot1L CKO mice, rAAV9-CMV-Dys $\Delta 3990$ (rAAV9-miniDmd), provides high expression of minidystrophin in all muscle tissues, including the heart (B Wang et al. 2008). To rescue CKO mice, rAAV9-miniDmd was administered at two different age groups - at either P3 via intraperitoneal (i.p.) injection or 2 mo via tail vein injection-and analyzed by ECHO. As shown in Table 2, cardiac function (EF and FS) is restored in CKO rescued mice injected at P3 (cf. Tables 1 and 2). Additionally, increases in LVID, LV Vol, and LV mass are significantly reduced by expression of minidystrophin (cf. Tables 1 and 2). Similar improvements were also observed in adult mice rescued at 2 mo of age (cf. Tables 1 and 2). Most significantly, adult rescued mice are able to survive past the second stage of lethality with no impairments in cardiac function (Table 2, $8 \mathrm{mo}$ ).

In addition to ECHO analysis, EKG of rescued $\mathrm{CKO}$ mice was also analyzed. At $5 \mathrm{mo}$, during the second stage of lethality, EKGs were obtained from mice rescued at P3. The results demonstrate that RR interval (Fig. 5A), PR interval (Fig. 5B), P duration (Fig. 5C), and QRS interval (Fig. 5D) were restored in the CKO mice. For mice rescued as adults, EKG was analyzed at $5 \mathrm{mo}$ and $8 \mathrm{mo}$ of age. The RR interval (Fig. 5E), P duration (Fig. 5G), and QRS interval (Fig. 5H) were restored in these mice, while PR intervals improved partially (cf. $P$-values in Figs. 5B, and $3 \mathrm{C})$. In addition, heart blocks observed prior to injection were no longer present in rescued CKO mice, as indicated by the EKG images and echocardiograms of the same mice before and after treatment (Supplemental Fig. 6A,B). Collectively, the above studies demonstrate that the functional defects caused by DOT1L deficiency in car- diomyocytes can be largely rescued by postnatal expression of Dmd, supporting that Dmd is a key DOT1L target in cardiomyocytes.

\section{Discussion}

DOT1L is the only known H3K79 methyltransferase and is conserved from yeast to humans. It is highly expressed in the heart, blood cells, and testis, although its expression in mammals is ubiquitous. Germline KO of Dot $1 \mathrm{~L}$ has been shown to be embryonic-lethal with cardiovascular and hematopoietic defects. In this study, we demonstrate that DOT1L H3K79 methyltransferase activity is vital for cardiac function in the mouse using a cardiacspecific KO model. DOT1L loss-of-function results in postnatal and adult lethality from DCM and CHF.

\section{The Dot1L CKO mouse is a useful model for understanding DCM}

Cardiac-specific loss of DOT1L H3K79 methyltransferase activity caused gross changes in cardiac growth and shape that are reminiscent of dilated cardiomyopathy. DCM is a disease of the heart muscle characterized by enlargement of one or both heart chambers, eccentric hypertrophy, interstitial fibrosis, systolic dysfunction, and conduction defects. In this study, we show that Dot1L CKO mice hearts are spherical in shape with enlarged chamber volumes and increased mass. Through immunostaining, we demonstrate that eccentric hypertrophy, increased proliferation, and reactive fibrosis may contribute to the increase in heart mass. In addition, a significant increase in cellular apoptosis was observed in CKO hearts. Finally, EKG and ECHO analyses revealed severe defects in

Table 2. Heart function of $r A A V$-miniDmd rescued CKO mice as measured by ECHO

\begin{tabular}{|c|c|c|c|c|c|c|c|c|c|}
\hline & & $\mathrm{EF}$ & FS & $\begin{array}{l}\text { LVID; d } \\
(\mathrm{mm})\end{array}$ & $\begin{array}{l}\text { LVID; s } \\
(\mathrm{mm})\end{array}$ & $\begin{array}{l}\text { LV Vol: d } \\
\qquad(\mu \mathrm{L})\end{array}$ & $\begin{array}{l}\text { LV Vol; s } \\
\quad(\mu \mathrm{L})\end{array}$ & LV mass & $n$ \\
\hline \multicolumn{10}{|c|}{ rAAV-Dmd at P3 } \\
\hline \multicolumn{10}{|l|}{$2 \mathrm{mo}$} \\
\hline & Wild type & $85.85 \% \pm 2.79 \%$ & $53.43 \% \pm 3.32 \%$ & $2.57 \pm 0.23$ & $1.20 \pm 0.18$ & $24.25 \pm 5.29$ & $3.54 \pm 1.31$ & $75.83 \pm 8.52$ & 5 \\
\hline & $\mathrm{CKO}$ & $79.53 \% \pm 6.76 \%$ & $46.97 \% \pm 6.59 \%$ & $2.77 \pm 0.35$ & $1.48 \pm 0.36$ & $29.59 \pm 9.75$ & $6.51 \pm 4.12$ & $82.19 \pm 14.13$ & 4 \\
\hline & $P$-value & ns & ns & ns & ns & ns & ns & ns & \\
\hline \multicolumn{10}{|l|}{$5 \mathrm{mo}$} \\
\hline & Wild type & $83.00 \% \pm 0.92 \%$ & $50.40 \% \pm 0.66 \%$ & $2.90 \pm 0.33$ & $1.44 \pm 0.17$ & $32.70 \pm 9.43$ & $5.64 \pm 1.82$ & $78.30 \pm 15.62$ & 5 \\
\hline & CKO & $78.47 \% \pm 11.52 \%$ & $47.81 \% \pm 12.36 \%$ & $3.10 \pm 0.46$ & $1.66 \pm 0.60$ & $39.38 \pm 14.11$ & $9.51 \pm 7.08$ & $103.62 \pm 29.65$ & 4 \\
\hline & $P$-value & ns & ns & ns & ns & ns & $\mathrm{ns}$ & $\mathrm{ns}$ & \\
\hline \multirow{2}{*}{\multicolumn{10}{|c|}{$\frac{\text { rAAV-Dmd at } 2 \mathrm{mo}}{5 \mathrm{mo}}$}} \\
\hline & & & & & & & & & \\
\hline & Wild type & $73.47 \% \pm 17.81 \%$ & $42.62 \% \pm 14.20 \%$ & $2.79 \pm 0.22$ & $1.62 \pm 0.54$ & $29.57 \pm 6.05$ & $8.61 \pm 7.53$ & $78.83 \pm 6.95$ & 3 \\
\hline & CKO & $82.87 \% \pm 3.53 \%$ & $50.39 \% \pm 4.07 \%$ & $2.81 \pm 0.12$ & $1.40 \pm 0.16$ & $30.04 \pm 3.14$ & $5.27 \pm 1.54$ & $104.25 \pm 9.60$ & 3 \\
\hline & $P$-value & $\mathrm{ns}$ & ns & $\mathrm{ns}$ & ns & ns & ns & ns & \\
\hline \multicolumn{10}{|l|}{$8 \mathrm{mo}$} \\
\hline & Wild type & $88.29 \% \pm 1.03 \%$ & $57.14 \% \pm 1.21 \%$ & $3.12 \pm 0.25$ & $1.34 \pm 0.14$ & $38.69 \pm 7.38$ & $4.57 \pm 1.24$ & $84.01 \pm 18.93$ & 3 \\
\hline & СKO & $83.32 \% \pm 2.13 \%$ & $50.97 \% \pm 2.22 \%$ & $3.15 \pm 0.25$ & $1.55 \pm 0.20$ & $40.30 \pm 8.67$ & $6.87 \pm 2.44$ & $120.48 \pm 19.58$ & 3 \\
\hline & $P$-value & ns & ns & $\mathrm{ns}$ & $\mathrm{ns}$ & $\mathrm{ns}$ & $\mathrm{ns}$ & $\mathrm{ns}$ & \\
\hline
\end{tabular}

To perform postnatal rescue, pups at P3 were administered rAAV-Dmd via intraperitoneal injection. To perform adult rescue, mice at 2 mo of age were administered rAAV-Dmd via tail vein injection. (EF) Ejection fraction; (FS) fractional shortening; (LVID) left ventricular internal diameter; (LV Vol) left ventricular volume; (LV mass) left ventricular mass (AW) corrected; (d) end diastolic; (s) end systolic. 

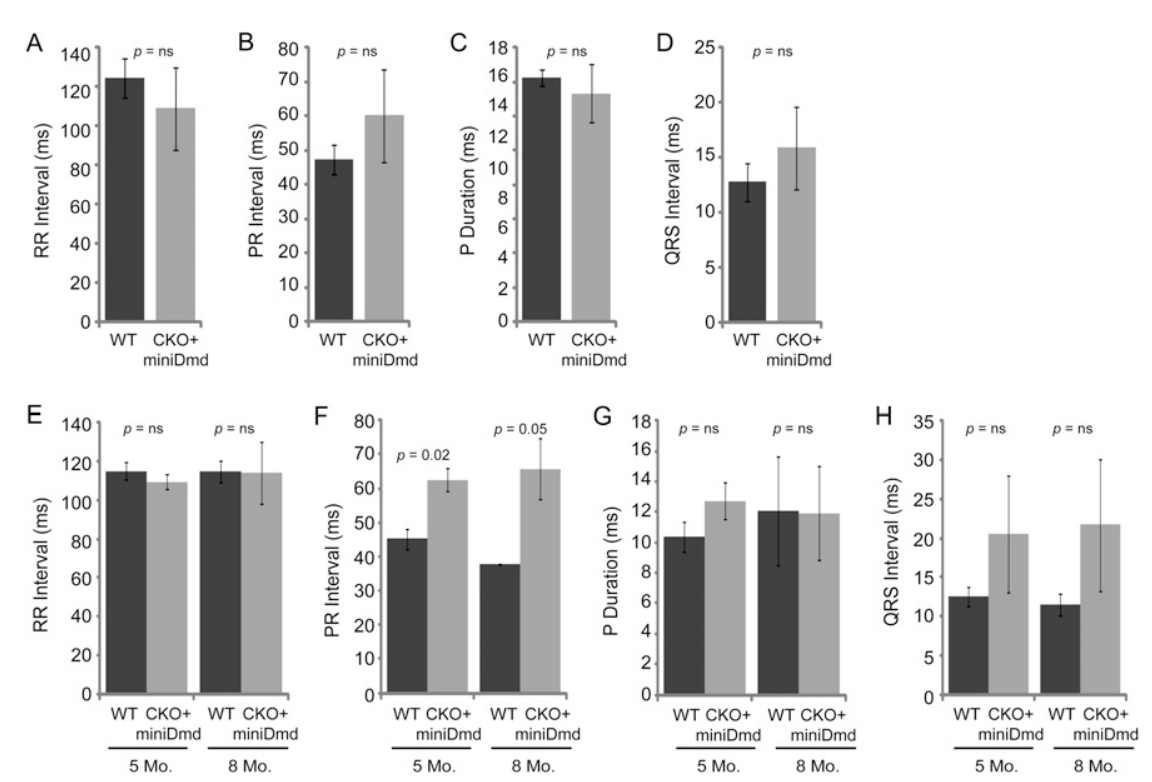

Figure 5. Rescue of electrical conduction in CKO mice by expression of minidystrophin gene. $(A-D)$ The defective function of the CKO heart can be rescued by expression of a minidystrophin gene when injected at P3 and analyzed at 5 mo of age, as indicated by the lack of significant difference between wild-type (WT) and CKO rescued mice. $(E-H)$ Additionally, minidystrophin can rescue adult $\mathrm{CKO}$ mice injected at 2 mo in terms of RR interval $(E)$, P-wave duration $(G)$, and QRS interval $(H)$. $(F)$ In addition, PR interval was partially rescued, as the difference observed is less than without miniDmd. $(P=0.02$ with rescue vs. $P=0.00014$ [Fig. $3 \mathrm{C}]$ without rescue at $5 \mathrm{mo})$. (E,F) At 8 mo of age, past the second stage of lethality, CKO + miniDmd mice still maintain similar rescued levels of electrical conduction performance. cardiac force transmission and output. Collectively, these data support that loss-of-function of DOT1L in cardiomyocytes results in phenotypes similar to those observed in DCM patients, making our mouse a valuable model for understanding DCM.

\section{Dystrophin is a key target mediating DOT1L function in the heart}

As the only known H3K79 methyltransferase, DOT1L is thought to play a genome-wide role in transcriptional regulation. Therefore, it may be inferred that loss of DOT1L enzymatic activity would silence a large number of genes vital for cardiac function. Microarray analysis revealed 751 down-regulated probes corresponding to 471 genes in CKO hearts. However, only two of these genes have been directly linked to DCM in mice and humans: Ttn and Dmd. Our histopathology data, including myocyte loss and remodeling, are consistent with a Dmd deficiency (Heydemann and McNally 2007) and not loss of Ttn, since sarcomeres remain normal.

We demonstrate that cardiac Dmd expression correlates with DOT1L-mediated H3K79 methylation. In addition, we show that DOT1L methyltransferase activity regulates $\mathrm{Dm} d$ transcription in C2C12 myoblast cells, and that exogenous Flag-DOT1L is localized to the Dmd locus. Collectively, these data conclusively demonstrate that DOT1L is a transcriptional regulator directly involved in Dmd expression. While other genes regulated by DOT1L may contribute to the DCM phenotype observed in CKO mice, the fact that the cardiac functional defects can be rescued by expression of a minidystrophin supports that Dmd is a critical target mediating DOT1L function in the heart.

In the $m d x$ mouse, a nonsense mutation results in the loss of Dmd expression in all muscle cells. Surprisingly, these mice do not develop severe DCM phenotypes (Hoffman et al. 1987; Grady et al. 1997), while DOT1L deficiency-caused Dmd down-regulation does. Since the
DOT1L deficiency in CKO mice occurs only in cardiomyocytes, Dmd expression is retained in CKO skeletal muscle, allowing for normal levels of exercise. The increased exercise in CKO mice compared with $m d x$ mice causes additional workload and stress on the heart, which would escalate the severity of DCM. Indeed, it has been reported that targeted repair in $m d x$ mice using a skeletal muscle-restricted minidystrophin transgene significantly enhanced cardiac injury and DCM (Townsend et al. 2008).

The apparent inconsistency between CKO and $m d x$ mice can also be explained by the lack of a similar compensation mechanism. Previous studies have demonstrated that loss of Dmd expression in the $m d x$ mouse is compensated by up-regulation of Utrophin (Utrn), an autosomal Dmd homolog (Deconinck et al. 1997; Grady et al. 1997). However, this compensation mechanism does not seem to exist in CKO mice, as DOT1L deficiency did not cause up-regulation of Utrn (Supplemental Fig. 5). Thus, the Dot1L CKO mouse may serve as a useful model for comparative analysis of the molecular mechanisms underlying the regulation of Utrn.

\section{A potential link between DOT1L and DCM/Duchenne muscular dystrophy (DMD)}

CHF is a common manifestation of cardiomyopathy, a disease caused by malfunction of the heart muscle (Seidman and Seidman 2001; Liew and Dzau 2004). DCM is the most common form of cardiomyopathy, affecting 36.5 out of 100,000 people (Seidman and Seidman 2001; Liew and Dzau 2004; Luk et al. 2009). Although extensive work has been performed to identify signature DCM genes through global expression profiling (Barrans et al. 2002; Barth et al. 2006; Camargo and Azuaje 2008), little effort has been focused on the epigenetic contribution, with the exception of histone acetylation (Zhang et al. 2002; Kook et al. 2003; Montgomery et al. 2007; Ha et al. 2010; Hang et al. 2010). With regard to histone 
methylation, only two studies have investigated changes in methylation patterns in heart failure (Kaneda et al. 2009; Movassagh et al. 2010). However, whether it directly contributes to the development of DCM is not known.

The demonstration that loss of DOT1L enzymatic activity results in DCM not only establishes a connection between dysregulation of histone methylation to DCM, but also raises the possibility that malfunction of DOT1L might account for some DCM patients. To explore this possibility, we analyzed hDOT1L expression level in idiopathic DCM $(n=27)$ and normal $(n=11)$ myocardial samples from publically available microarray data (http:// cardiogenomics.med.harvard.edu/project-detail?project_ $\mathrm{id}=229$ ). This analysis indicates that DOT1L is downregulated in idiopathic DCM patients with all Affymetrix probe sets ( $n=11$ probes per set) (Supplemental Fig. 8), supporting the notion that dysfunction of DOT1L may be a contributing factor to human idiopathic DCM. Mutations in Dmd is also the cause of both DMD and Becker muscular dystrophy (BMD), affecting one out of 3500 males (Hoffman et al. 1987). Up to $90 \%$ of those patients manifest cardiomyopathies, and many die of heart failure (Connuck et al. 2008). In this study, we established that DOT1L regulates Dmd expression in both cardiac and C2C12 cells, suggesting that a DOT1L deficiency may contribute to DCM and human muscular dystrophy. Future studies should reveal whether DOT1L is genetically linked to DCM, DMD, and BMD in human patients.

\section{Materials and methods}

\section{Generation of cardiac-specific Dot1L CKO mice}

The targeting vector and generation of DOT1L chimeric mice have been described previously (Jones et al. 2008). DOT1L $\mathrm{L}^{210 x /+}$

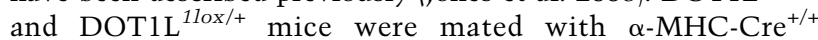
transgenic mice to obtain DOT1L $\mathrm{L}^{210 x /+} ; \alpha-\mathrm{MHC}-\mathrm{Cre}^{+/+}$and DOT1L $\mathrm{L}^{110 x /+} ; \alpha-$ MHC-Cre ${ }^{+/+}$mating pairs. Mice were kept on a $129 \mathrm{SvJ}$, C57BL/6J mixed background. DOT1L $210 x / 110 x ; \alpha-M H C-$ $\mathrm{Cre}^{+/+}$mice and DOT1L $\mathrm{L}^{210 x / 210 x} ; \alpha-\mathrm{MHC}-\mathrm{Cre}^{+/+}$mice were used as CKO mice. Upon Cre recombination, exons 5 and 6 were excised from the DOT1L locus. After splicing of the DOT1L transcript from the CKO allele, exons 4 and 7 of the mature mRNA were translated in-frame, generating a mutant DOT1L protein lacking a portion of the SAM-binding motif. All mice procedures were performed following the guidelines set by the Institutional Animal Care and Use Committee.

\section{ECHO and EKG}

Experiments were performed at the Mouse Cardiovascular Models Core Facility at University of North Carolina at Chapel Hill (UNC-CH) or in the laboratory of Dr. Xiao Xiao (UNC-CH). To restrain postnatal pups, paws were taped to a plastic board. For adult mice, soft cotton thread loops were placed around each leg, just proximal to the paw, and gently snugged with a plastic slider. The distal ends of the threads were placed in notches cut into a plastic board and gently tightened to hold the animal in a supine position to prevent self-mutilation of the forelimbs. Warmed Aquasonic gel was applied over the thorax and a 30$\mathrm{MHz}$ probe was positioned over the chest in a parasternal position. Long and short axis B-mode and M-mode images were recorded. Upon completion of the procedure, the gel was wiped off and the animal was returned to its cage housed in a warm chamber. Time of restraint was 5 min or less. For EKG, mice were anesthetized with inhaled isoflurane. Mice were taped to a warmed mouse board and their body temperature was monitored with a rectal probe and maintained at $37^{\circ} \mathrm{C} \pm 1{ }^{\circ} \mathrm{C}$ throughout the procedure. Thin (29 gauge) sharpened needle electrodes were passed subcutaneously into the area at the ventral base of each limb. After three leads were recorded, the needles were removed and the animals were allowed to recover.

\section{Histology and immunofluorescence staining}

For all tissue sectioning, beating hearts were harvested from euthanized mice and immediately transferred to ice-cold PBS containing $1 \mathrm{M} \mathrm{KCl}$ until the hearts stopped beating at diastole state. For H\&E staining, hearts were fixed in $4 \%$ paraformaldehyde overnight and paraffin-embedded. Serial sections at $5-\mu \mathrm{m}$ thickness were used for staining. Hearts used for all immunofluorescence staining were fixed in 4\% PFA and subjected to sequential incubation with $10 \%, 20 \%$, and $30 \%$ sucrose in PBS at $4^{\circ} \mathrm{C}$. Hearts were then flash-frozen in OCT medium using liquid nitrogen, and frozen serial sections of $5-\mu \mathrm{m}$ thickness were prepared using a Leica Cryostat. Primary antibodies used for staining include anti-Dystrophin (Abcam, ab15277-500), antiHSPG2 (Neomarkers, RT-794), anti-a-Laminin (Chemicon, AB2034), anti-H3K79me2/3 (Abcam, ab2621-100), and antiKi-67 (Abcam, ab15580). Secondary antibodies used were Alexa Fluor 594 goat anti-rat IgG (Invitrogen, A21212), Alexa Fluor 594 donkey anti-rabbit IgG (Invitrogen, A21207), and Alexa Fluor 488 donkey anti-rabbit IgG (Invitrogen, A21206). Sections were counterstained with DAPI.

\section{TUNEL assay}

TUNEL staining was performed on frozen sections using the ApopTag Fluorescein In Situ Apoptosis Detection kit (Millipore, S7110) and counterstained with DAPI

\section{Masson's trichrome staining}

Paraffin sections, $5 \mu \mathrm{m}$ thick, of hearts from 5-mo-old mice were used for staining. Masson's Trichrome Stain kit was purchased from Dako (AR173), and procedures were followed according to the manufacturer's specifications, manually, without an Artisan staining system.

\section{TEM}

Wild-type and CKO mice were injected with $25 \mathrm{U}$ of heparin intramuscular prior to euthanasia by isofluorane overdose. The hearts were quickly exposed and perfused with $3 \mathrm{mg} / \mathrm{mL}$ 2,3-Butanedione monoxime in Hepes-buffered Krebs solution, followed by perfusion with $2 \%$ glutaraldehyde plus $6 \%$ sucrose in $75 \mathrm{mM}$ Na-Cacodylate buffer (pH 7.4) supplemented with $3 \mathrm{mg} / \mathrm{mL}$ BDM and $0.1 \%$ tannic acid, followed by $2 \%$ osmium tetroxide. Samples were stained with uranyl acetate en bloc. Images were acquired on a Zeiss EM 910 transmission electron microscope using a Gatan SC1000 digital camera.

\section{Microarray and RT-qPCR analysis}

Hearts were flash-frozen in liquid nitrogen and ground to a fine powder. Total RNA was purified from tissue powder using the Qiagen RNeasy kit. RNA from three hearts, 1 ug each, was pooled together. Four pairs of pooled RNA, representing a total of 
12 wild-type and $12 \mathrm{CKO}$ hearts, were used for gene expression analysis. Samples were submitted to the UNC Genomics and Bioinformatics Core Facility for RNA labeling, amplification, hybridization, and scanning. The dual-color Agilent 4X44K Whole Mouse Genome Array system was used. All reagents were purchased from Agilent, and procedures were followed according to Agilent's protocols. Raw data were uploaded into the UNC Microarray Database (Agi-Scanner-Reg-MM-4X44KD20060807-BARCODE14868; Slide Run US82800149). Data were analyzed using the SAM algorithm (tail strength $51.4 \%$, SE $63.8 \%$ ) to yield 1379 significant probes with a median number of false positives $(0.81)$ and a false discovery rate of $0.06 \%$. For RT-qPCR analysis, RNA prepared above was treated with DNase I, and first strand DNA synthesis was performed using Improm II (Promega). SYBR GreenER qPCR SuperMix (Invitrogen) was used for qPCR. Relative expression was normalized to gapdh. Primers are shown in Supplemental Table 3.

\section{Micro-ChIP and Western blot}

Micro-ChIP from frozen heart biopsies was performed as described previously (Dahl and Collas 2008) with the following modifications. Frozen hearts from P10 pups were ground to a fine powder prior to formaldehyde cross-linking. DNA was fragmented into $300-500$ base pairs (bp) by sonication at $15 \%$ power $(2 \times 15 \mathrm{sec}, 0.5 \mathrm{sec}$ on and $2 \mathrm{sec}$ off $)$. Immunoprecipitation was performed using anti-H3K $79 \mathrm{me} 2 / 3$ (Abcam) and anti-rabbit IgG (Santa Cruz Biotechnology, sc-2027). Chromatin immunoprecipitated samples were washed twice with low-salt (140 mM NaCl) RIPA buffer, once with high-salt ( $500 \mathrm{mM} \mathrm{NaCl}$ ) RIPA buffer, and twice with TE buffer. DNA was purified using the Chelex-100 method, and qPCR was performed using the ChIP primers listed in Supplemental Table 3. For Western blot analysis, P1 frozen hearts were ground to a fine powder for histone extraction and Western blot as described previously (Fang et al. 2002).

\section{C2C12 KD and rescue}

C2C12 cells were maintained in Dulbecco's modified Eagle's medium supplemented with $10 \%$ FBS and $1 \%$ penicillin/streptomycin. To establish stable KD cell lines, the lentivirus pTYEF1a system was used as described previously (Cao et al. 2008; He et al. 2008). To knock down mDOT1L, a shRNA 19mer was designed targeting the coding region $\left(5^{\prime}\right.$-GGAGCCAGATCTCA GAGAA-3'). The control shRNA is targeted against a bacterial protein with no mouse or human homology $\left(5^{\prime}\right.$-GTTCAGATGT GCGGCGAGT-3'). KD cells were selected and maintained in medium containing $2 \mu \mathrm{g} / \mathrm{mL}$ puromycin. For rescue experiments, $\mathrm{KD}$ cells were infected with retrovirus expressing wild-type and catalytic mutant Flag-tagged human DOT1L (Flag-hDOT1L) as described previously (Okada et al. 2005). Retrovirus-infected cells were selected and maintained in medium containing $2 \mu \mathrm{g} / \mathrm{mL}$ blasticidin. RNA was isolated using RNeasy kit from Qiagen. The same micro-ChIP procedure described above was followed for ChIP using 50,000 cells per sample. Dynabeads Protein A and M2 Flag antibody (Sigma, F3165) were also used.

\section{Postnatal rescue of CKO mice with $r A A V$-miniDmd}

The functional miniature version of human dystrophin gene $\Delta 3990$ (miniDmd) under the transcriptional control of CMV promoter has been described previously (Wang et al. 2000). The miniDmd gene expression cassette was packaged into AAV9 vector using the helper-free, triple plasmids transfection method and was purified by double CsCl density ultracentrifugation (Xiao et al. 1998). The rAAV9-CMV-miniDmd titers were de- termined by DNA dot blot at $\sim 1 \times 10^{13}$ viral genome (v.g.) particles per milliliter. For 3-d-old neonatal CKO mice, a single dose of $1 \times 10^{11}$ v.g. per mouse in $50 \mu \mathrm{L}$ was injected i.p. For 2-mo-old CKO mice, a single dose of $1 \times 10^{12} \mathrm{v}$.g. per mouse in $600 \mu \mathrm{L}$ was injected via tail vein.

\section{Statistics}

Indicated $P$-values were calculated using a two-tailed $t$-test.

\section{Acknowledgments}

We thank Jackie Kylander, Kristine Porter, and Mauricio Rojas at the UNC-CH Mouse Cardiovascular Models Core Facility for performing ECHO on P10 pups and EKG on adult control mice; Kai Xia for help with the microarray data analysis; Jin He for help in EKG data analysis; and Kwon-Ho Hong for critical reading of the manuscript. The work is supported by an NIH grant (CA119133). A.T.N is a recipient of the Predoctoral Fellowship from the American Heart Association. Y.Z. is an Investigator of the Howard Hughes Medical Institute.

\section{References}

Abel ED, Kaulbach HC, Tian R, Hopkins JC, Duffy J, Doetschman T, Minnemann T, Boers ME, Hadro E, Oberste-Berghaus C, et al. 1999. Cardiac hypertrophy with preserved contractile function after selective deletion of GLUT4 from the heart. J Clin Invest 104: 1703-1714.

Ahuja P, Sdek P, MacLellan WR. 2007. Cardiac myocyte cell cycle control in development, disease, and regeneration. Physiol Rev 87: 521-544.

Banerjee I, Fuseler JW, Price RL, Borg TK, Baudino TA. 2007. Determination of cell types and numbers during cardiac development in the neonatal and adult rat and mouse. Am I Physiol Heart Circ Physiol 293: H1883-H1891. doi: 10.1152/ajpheart.00514.2007.

Barrans JD, Allen PD, Stamatiou D, Dzau VJ, Liew CC. 2002. Global gene expression profiling of end-stage dilated cardiomyopathy using a human cardiovascular-based cDNA microarray. Am J Pathol 160: 2035-2043.

Barry ER, Krueger W, Jakuba CM, Veilleux E, Ambrosi DJ, Nelson CE, Rasmussen TP. 2009. ES cell cycle progression and differentiation require the action of the histone methyltransferase Dot1L. Stem Cells 27: 1538-1547.

Barski A, Cuddapah S, Cui K, Roh TY, Schones DE, Wang Z, Wei G, Chepelev I, Zhao K. 2007. High-resolution profiling of histone methylations in the human genome. Cell 129: 823837.

Barth AS, Kuner R, Buness A, Ruschhaupt M, Merk S, Zwermann L, Kaab S, Kreuzer E, Steinbeck G, Mansmann U, et al. 2006. Identification of a common gene expression signature in dilated cardiomyopathy across independent microarray studies. J Am Coll Cardiol 48: 1610-1617.

Camargo A, Azuaje F. 2008. Identification of dilated cardiomyopathy signature genes through gene expression and network data integration. Genomics 92: 404-413.

Cao R, Wang H, He J, Erdjument-Bromage H, Tempst P, Zhang Y. 2008. Role of hPHF1 in H3K27 methylation and Hox gene silencing. Mol Cell Biol 28: 1862-1872.

Cohn JN, Ferrari R, Sharpe N. 2000. Cardiac remodeling—Concepts and clinical implications: A consensus paper from an international forum on cardiac remodeling. Behalf of an International Forum on Cardiac Remodeling. I Am Coll Cardiol 35: 569582.

Conde F, Refolio E, Cordon-Preciado V, Cortes-Ledesma F, Aragon L, Aguilera A, San-Segundo PA. 2009. The Dot1 
histone methyltransferase and the Rad9 checkpoint adaptor contribute to cohesin-dependent double-strand break repair by sister chromatid recombination in Saccharomyces cerevisiae. Genetics 182: 437-446.

Connuck DM, Sleeper LA, Colan SD, Cox GF, Towbin JA, Lowe AM, Wilkinson JD, Orav EJ, Cuniberti L, Salbert BA, et al. 2008. Characteristics and outcomes of cardiomyopathy in children with Duchenne or Becker muscular dystrophy: A comparative study from the Pediatric Cardiomyopathy Registry. Am Heart J 155: 998-1005.

Dahl JA, Collas P. 2008. A rapid micro chromatin immunoprecipitation assay (microChIP). Nat Protoc 3: 10321045.

Deconinck AE, Rafael JA, Skinner JA, Brown SC, Potter AC, Metzinger L, Watt DJ, Dickson JG, Tinsley JM, Davies KE. 1997. Utrophin-dystrophin-deficient mice as a model for Duchenne muscular dystrophy. Cell 90: 717-727.

de Leeuw N, Ruiter DJ, Balk AH, de Jonge N, Melchers WJ, Galama JM. 2001. Histopathologic findings in explanted heart tissue from patients with end-stage idiopathic dilated cardiomyopathy. Transpl Int 14: 299-306.

Fang J, Feng Q, Ketel CS, Wang H, Cao R, Xia L, ErdjumentBromage H, Tempst P, Simon JA, Zhang Y. 2002. Purification and functional characterization of SET8, a nucleosomal histone H4-lysine 20-specific methyltransferase. Curr Biol 12: $1086-1099$.

Feinberg AP, Oshimura M, Barrett JC. 2002. Epigenetic mechanisms in human disease. Cancer Res 62: 6784-6787.

Feng Q, Wang H, Ng HH, Erdjument-Bromage H, Tempst P, Struhl K, Zhang Y. 2002. Methylation of H3-lysine 79 is mediated by a new family of HMTases without a SET domain. Curr Biol 12: 1052-1058.

Feng Y, Yang Y, Ortega MM, Copeland JN, Zhang M, Jacob JB, Fields TA, Vivian JL, Fields PE. 2010. Early mammalian erythropoiesis requires the Dot1L methyltransferase. Blood 116: 4483-4491.

Galvagni F, Lestingi M, Cartocci E, Oliviero S. 1997. Serum response factor and protein-mediated DNA bending contribute to transcription of the dystrophin muscle-specific promoter. Mol Cell Biol 17: 1731-1743.

Gerull B, Gramlich M, Atherton J, McNabb M, Trombitas K, Sasse-Klaassen S, Seidman JG, Seidman C, Granzier H, Labeit S, et al. 2002. Mutations of TTN, encoding the giant muscle filament titin, cause familial dilated cardiomyopathy. Nat Genet 30: 201-204.

Giannattasio M, Lazzaro F, Plevani P, Muzi-Falconi M. 2005. The DNA damage checkpoint response requires histone H2B ubiquitination by Rad6-Bre1 and H3 methylation by Dot1. I Biol Chem 280: 9879-9886.

Gotthardt M, Hammer RE, Hubner N, Monti J, Witt CC, McNabb M, Richardson JA, Granzier H, Labeit S, Herz J. 2003. Conditional expression of mutant M-line titins results in cardiomyopathy with altered sarcomere structure. J Biol Chem 278: 6059-6065.

Grady RM, Teng H, Nichol MC, Cunningham JC, Wilkinson RS, Sanes JR. 1997. Skeletal and cardiac myopathies in mice lacking utrophin and dystrophin: A model for Duchenne muscular dystrophy. Cell 90: 729-738.

Ha CH, Kim JY, Zhao J, Wang W, Jhun BS, Wong C, Jin ZG. 2010. PKA phosphorylates histone deacetylase 5 and prevents its nuclear export, leading to the inhibition of gene transcription and cardiomyocyte hypertrophy. Proc Natl Acad Sci 107: 15467-15472.

Handel AE, Ebers GC, Ramagopalan SV. 2009. Epigenetics: Molecular mechanisms and implications for disease. Trends Mol Med 16: 7-16.
Hang CT, Yang J, Han P, Cheng HL, Shang C, Ashley E, Zhou B, Chang CP. 2010. Chromatin regulation by Brg1 underlies heart muscle development and disease. Nature 466: 62-67.

Hatcher CJ, Basson CT. 2009. Specification of the cardiac conduction system by transcription factors. Circ Res 105: 620-630.

He J, Kallin EM, Tsukada Y, Zhang Y. 2008. The H3K36 demethylase $\mathrm{Jhdm} 1 \mathrm{~b} / \mathrm{Kdm} 2 \mathrm{~b}$ regulates cell proliferation and senescence through p15(Ink4b). Nat Struct Mol Biol 15: 1169-1175.

Heydemann A, McNally EM. 2007. Consequences of disrupting the dystrophin-sarcoglycan complex in cardiac and skeletal myopathy. Trends Cardiovasc Med 17: 55-59.

Hoffman EP, Brown RH Jr, Kunkel LM. 1987. Dystrophin: The protein product of the Duchenne muscular dystrophy locus. Cell 51: 919-928.

Houweling AC, van Borren MM, Moorman AF, Christoffels VM. 2005. Expression and regulation of the atrial natriuretic factor encoding gene Nppa during development and disease. Cardiovasc Res 67: 583-593.

Jones B, Su H, Bhat A, Lei H, Bajko J, Hevi S, Baltus GA, Kadam S, Zhai H, Valdez R, et al. 2008. The histone H3K79 methyltransferase Dot1L is essential for mammalian development and heterochromatin structure. PLoS Genet 4: e1000190. doi: 10.1371/journal.pgen.1000190.

Kajstura J, Leri A, Finato N, Di Loreto C, Beltrami CA, Anversa P. 1998. Myocyte proliferation in end-stage cardiac failure in humans. Proc Natl Acad Sci 95: 8801-8805.

Kaneda R, Takada S, Yamashita Y, Choi YL, Nonaka-Sarukawa M, Soda M, Misawa Y, Isomura T, Shimada K, Mano H. 2009. Genome-wide histone methylation profile for heart failure. Genes Cells 14: 69-77.

Karkkainen S, Peuhkurinen K. 2007. Genetics of dilated cardiomyopathy. Ann Med 39: 91-107.

Kimura, A. 2008. Molecular etiology and pathogenesis of hereditary cardiomyopathy. Circ J 72: A38-A48.

Knaapen MW, Davies MJ, De Bie M, Haven AJ, Martinet W, Kockx MM. 2001. Apoptotic versus autophagic cell death in heart failure. Cardiovasc Res 51: 304-312.

Kook H, Lepore JJ, Gitler AD, Lu MM, Wing-Man Yung W, Mackay J, Zhou R, Ferrari V, Gruber P, Epstein JA. 2003. Cardiac hypertrophy and histone deacetylase-dependent transcriptional repression mediated by the atypical homeodomain protein Hop. J Clin Invest 112: 863-871.

Kostin S, Hein S, Arnon E, Scholz D, Schaper J. 2000. The cytoskeleton and related proteins in the human failing heart. Heart Fail Rev 5: 271-280.

Kouzarides T. 2007. Chromatin modifications and their function. Cell 128: 693-705.

Krivtsov AV, Feng Z, Lemieux ME, Faber J, Vempati S, Sinha AU, Xia X, Jesneck J, Bracken AP, Silverman LB, et al. 2008. H3K79 methylation profiles define murine and human MLLAF4 leukemias. Cancer Cell 14: 355-368.

Krogan NJ, Dover J, Wood A, Schneider J, Heidt J, Boateng MA, Dean K, Ryan OW, Golshani A, Johnston M, et al. 2003. The Pafl complex is required for histone $\mathrm{H} 3$ methylation by COMPASS and Dotlp: Linking transcriptional elongation to histone methylation. Mol Cell 11: 721-729.

Lacoste N, Utley RT, Hunter JM, Poirier GG, Cote J. 2002. Disruptor of telomeric silencing-1 is a chromatin-specific histone H3 methyltransferase. I Biol Chem 277: 3042130424.

Liew CC, Dzau VJ. 2004. Molecular genetics and genomics of heart failure. Nat Rev Genet 5: 811-825.

Luk A, Ahn E, Soor GS, Butany J. 2009. Dilated cardiomyopathy: A review. J Clin Pathol 62: 219-225. 
Martin C, Zhang Y. 2005. The diverse functions of histone lysine methylation. Nat Rev Mol Cell Biol 6: 838-849.

Mohan M, Herz HM, Takahashi YH, Lin C, Lai KC, Zhang Y, Washburn MP, Florens L, Shilatifard A. 2010. Linking H3K79 trimethylation to Wnt signaling through a novel Dot1containing complex (DotCom). Genes Dev 24: 574-589.

Montgomery RL, Davis CA, Potthoff MJ, Haberland M, Fielitz J, Qi X, Hill JA, Richardson JA, Olson EN. 2007. Histone deacetylases 1 and 2 redundantly regulate cardiac morphogenesis, growth, and contractility. Genes Dev 21: 1790-1802.

Movassagh M, Choy MK, Goddard M, Bennett MR, Down TA, Foo RS. 2010. Differential DNA methylation correlates with differential expression of angiogenic factors in human heart failure. PLOS ONE 5: e8564. doi: 10.1371/journal.pone. 0008564.

Mueller D, Bach C, Zeisig D, Garcia-Cuellar MP, Monroe S, Sreekumar A, Zhou R, Nesvizhskii A, Chinnaiyan A, Hess JL, et al. 2007. A role for the MLL fusion partner ENL in transcriptional elongation and chromatin modification. Blood 110: 4445-4454.

$\mathrm{Ng} \mathrm{HH}$, Feng Q, Wang H, Erdjument-Bromage $\mathrm{H}$, Tempst $\mathrm{P}$, Zhang Y, Struhl K. 2002a. Lysine methylation within the globular domain of histone $\mathrm{H} 3$ by Dot1 is important for telomeric silencing and Sir protein association. Genes Dev 16: $1518-1527$.

Ng HH, Xu RM, Zhang Y, Struhl K. 2002b. Ubiquitination of histone H2B by Rad6 is required for efficient Dot1-mediated methylation of histone H3 lysine 79. I Biol Chem 277: 34655-34657.

Okada Y, Feng Q, Lin Y, Jiang Q, Li Y, Coffield VM, Su L, Xu G, Zhang Y. 2005. hDOT1L links histone methylation to leukemogenesis. Cell 121: 167-178.

Okada Y, Jiang Q, Lemieux M, Jeannotte L, Su L, Zhang Y. 2006. Leukaemic transformation by CALM-AF10 involves upregulation of Hoxa5 by hDOT1L. Nat Cell Biol 8: 1017-1024.

Olson EN. 2004. A decade of discoveries in cardiac biology. Nat Med 10: 467-474.

Peterson CL, Laniel MA. 2004. Histones and histone modifications. Curr Biol 14: R546-R551. doi: 10.1016/j.cub.2004.07. 007.

San-Segundo PA, Roeder GS. 2000. Role for the silencing protein Dotl in meiotic checkpoint control. Mol Biol Cell 11: 36013615.

Schubeler D, MacAlpine DM, Scalzo D, Wirbelauer C, Kooperberg C, van Leeuwen F, Gottschling DE, O'Neill LP, Turner BM, Delrow J, et al. 2004. The histone modification pattern of active genes revealed through genome-wide chromatin analysis of a higher eukaryote. Genes Dev 18: 1263-1271.

Seidman JG, Seidman C. 2001. The genetic basis for cardiomyopathy: From mutation identification to mechanistic paradigms. Cell 104: 557-567.

Singer MS, Kahana A, Wolf AJ, Meisinger LL, Peterson SE, Goggin C, Mahowald M, Gottschling DE. 1998. Identification of high-copy disruptors of telomeric silencing in Saccharomyces cerevisiae. Genetics 150: 613-632.

Steger DJ, Lefterova MI, Ying L, Stonestrom AJ, Schupp M, Zhuo D, Vakoc AL, Kim JE, Chen J, Lazar MA, et al. 2008. DOT1L/ KMT4 recruitment and H3K79 methylation are ubiquitously coupled with gene transcription in mammalian cells. Mol Cell Biol 28: 2825-2839.

Towbin JA, Bowles NE. 2006. Dilated cardiomyopathy: A tale of cytoskeletal proteins and beyond. I Cardiovasc Electrophysiol 17: 919-926.

Townsend D, Yasuda S, Li S, Chamberlain JS, Metzger JM. 2008. Emergent dilated cardiomyopathy caused by targeted repair of dystrophic skeletal muscle. Mol Ther 16: 832-835. van Leeuwen F, Gafken PR, Gottschling DE. 2002. Dotlp modulates silencing in yeast by methylation of the nucleosome core. Cell 109: 745-756.

Wang B, Li J, Xiao X. 2000. Adeno-associated virus vector carrying human minidystrophin genes effectively ameliorates muscular dystrophy in $\mathrm{mdx}$ mouse model. Proc Nat Acad Sci 97: 13714-13719.

Wang B, Li J, Fu FH, Chen C, Zhu X, Zhou L, Jiang X, Xiao X. 2008. Construction and analysis of compact muscle-specific promoters for AAV vectors. Gene Ther 15: 1489-1499.

Wang Z, Zang C, Rosenfeld JA, Schones DE, Barski A, Cuddapah S, Cui K, Roh TY, Peng W, Zhang MQ, et al. 2008. Combinatorial patterns of histone acetylations and methylations in the human genome. Nat Genet 40: 897-903.

Weinert S, Bergmann N, Luo X, Erdmann B, Gotthardt M. 2006. $M$ line-deficient titin causes cardiac lethality through impaired maturation of the sarcomere. J Cell Biol 173: 559-570.

Wood A, Schneider J, Dover J, Johnston M, Shilatifard A. 2003. The Pafl complex is essential for histone monoubiquitination by the Rad6-Brel complex, which signals for histone methylation by COMPASS and Dotlp. I Biol Chem 278: 34739-34742.

Wysocki R, Javaheri A, Allard S, Sha F, Cote J, Kron SJ. 2005. Role of Dot1-dependent histone H3 methylation in G1 and S phase DNA damage checkpoint functions of Rad9. Mol Cell Biol 25: 8430-8443.

Xiao X, Li J, Samulski RJ. 1998. Production of high-titer recombinant adeno-associated virus vectors in the absence of helper adenovirus. I Virol 72: 2224-2232.

Zhang CL, McKinsey TA, Chang S, Antos CL, Hill JA, Olson EN. 2002. Class II histone deacetylases act as signalresponsive repressors of cardiac hypertrophy. Cell 110: 479488. 


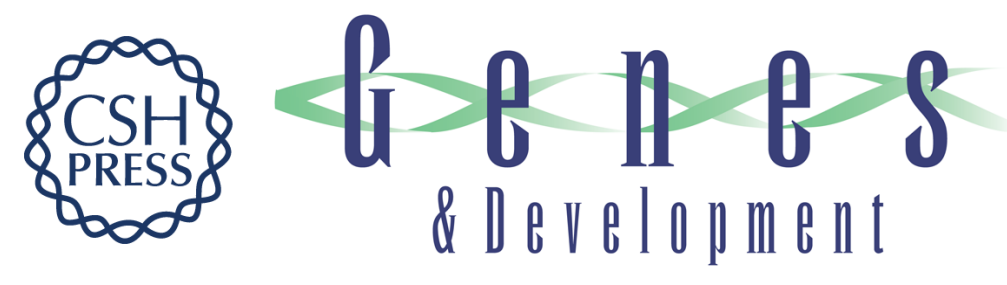

\section{DOT1L regulates dystrophin expression and is critical for cardiac function}

Anh T. Nguyen, Bin Xiao, Ronald L. Neppl, et al.

Genes Dev. 2011, 25:

Access the most recent version at doi:10.1101/gad.2018511

Supplemental http://genesdev.cshlp.org/content/suppl/2011/02/02/25.3.263.DC1
Material

License

Email Alerting Receive free email alerts when new articles cite this article - sign up in the box at the top Service right corner of the article or click here.

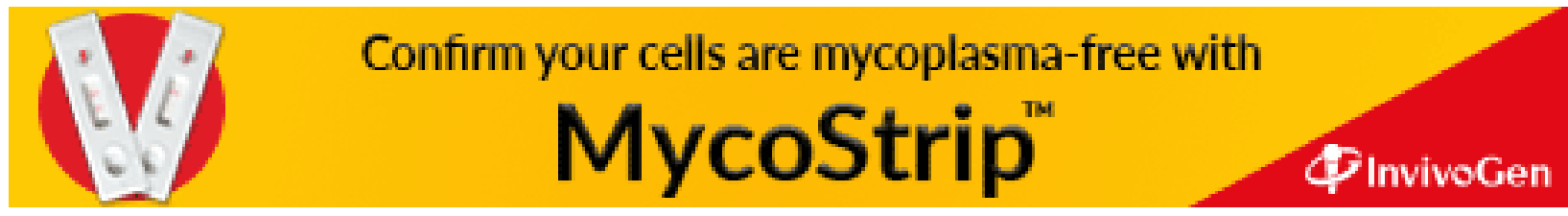

